\title{
ОПЫТ ЛЕЧЕНИЯ КИСТОЗНОГО МАКУЛЯРНОГО ОТЕКА У ПОДРОСТКА С САХАРНЫМ ДИАБЕТОМ 1 ТИПА
}

\author{
И.И. Штода, И.Ю. Черняк, Ю.Н. Антипова, Р.В. Иванова, М.Ю. Банова \\ ГБУз «Детская краевая клиническая больнича», г. Краснодар
}

Проблема СД, несмотря на достигнутые успехи в ее разрешении, остается актуальной. Наличие и прогрессирование осложнений СД у детей приводит к быстрой и стойкой инвалидизации. Одной из причин потери зрения является диабетическая ретинопатия (ДР).

Уровень хронической гипергликемии влияет не только на распространенность ДР, но и на ее структуру Чем длительнее нарушение углеводного обмена, тем выше распространенность и тяжесть изменений глазного дна. ДР характеризуются нарушением капиллярной перфузии, развитием внутриглазных новообразованных сосудов и ретинальным отеком в макулярной зоне. В патогенезе диабетического макулярного отека (ДМО) повышенная экспрессия эндотелиального фактора роста сосудов (vascular endothelial growth factor - VEGF),

КЛИНИЧЕСКИЙ СЛУчАЙ. Девочка 3., 17 лет, сахарный диабет с 2011 г. Назначена инсулинотерапия в дозе 0,7 ед/кг/сут. Мама и ребенок прошли обучение в школе диабета. В последующем отмечалось отсутствие контроля родителей за питанием ребенка, уровнем гликемии, рекомендации врачей не выполнялись. Госпитализация в эндокринологическое отделение нерегулярная в состоянии выраженной декомпенсации заболевания (2013, 2015, 2017 гг.).

В ноябре 2020 г. состояние резко ухудшилось, по тяжести состояния в экстренном порядке госпитализирована в ГБУЗ ДККБ с диагнозом: Сахарный диабет 1 тип, кетоацидоз. Вариабельность гликемии от 6,7-до 22,3 ммоль/л, НbА 1с 12\%, При обследовании выявлены осложнения: Диабетическая полинейропатия, сенсомоторная, смешанный вариант, дистальная. Непролиферативная диабетическая ретинопатия. Диабетический макулярный кистозный отек обоих глаз. Диабетическая хайропатия. Жировой гепатоз. Задержка физического развития. Задержка полового развития. Аменорея І. Хронический воспалительный процесс кожи передней поверхности правой голени. Миокардиодистрофия смешанного генеза. Сопутствующий: Латентный дефицит железа.

На первоначальном осмотре офтальмолога, отмечалось снижение зрения (Vis $\mathrm{OD}=0.4 \mathrm{H} / \mathrm{k}, \mathrm{OS}=0.3 \mathrm{H} /$ к.) и регидность радужных оболочек, при проведении ОКТ обнаружились изменения профиля макулярной области, кистозный отек, утолщение сетчатки в области фовеолы до 410 нм на правом глазу и 549 нм на левом глазу.

Получала лечение: интенсифицированную инсулинотерапию из расчета 1,0 ед/кг/веса(Аспарт, Гларгин)., тиоктовую кислоту, Кларуктам, вит группы В, субконъюнктивально - гентамицин + дексаметазон + мезатон, тобрадекс в инстилляциях. После проведенного лечения, нормализации показателей углеводного обмена отмечалось повышение остроты зрения: $\mathrm{Vis} O \mathrm{O}=0.8 \mathrm{OS}=0.8$.

По месту жительства показатели углеводного обмена поддерживались в пределах 6,0-11,0 ммоль/л, снизился уровень $\mathrm{HbA}_{1 с} 9,0 \%$.

При повторной госпитализации в офтальмологическое отделение ГБУЗ ДККБ проведено эндовитриальное введение anti-VEGF препарата Эйлеа (Афлиберцепт). Проведено ОКТ заднего отрезка до оперативного лечения и после введения препарата.: толщина макулярной зоны до введения: $\mathrm{OD}=488$ мкм; $\mathrm{OS}=590$ мкм. Через сутки после введения толщина макулярной зоны уменьшилась и составила $\mathrm{OD}=325$ мкм; $\mathrm{OS}=413$ мкм. Vis $\mathrm{OD}=0,8 \mathrm{H} / \mathrm{k} ; \mathrm{OS}=0,8 \mathrm{H} / \mathrm{k}$.

Выводы. Раннее выявление диабетической ретинопатии, своевременное лечение позволяет длительно сохранить зрительные функции и предотвратить развитие диабетического макулярного отека, являющегося в настоящее время одним из наиболее редких осложнений сахарного диабета в детском возрасте.

Мультидисциплинарный подход к лечению пациента позволяет предотвратить инвалидизацию, включая слепоту у детей с сахарным диабетом. Важную роль также играет комплаентность врача и родителей пациентов. Необходимо соблюдать режим питания и инсулинотерапии, поддерживать гликемию в пределах целевых значений, а также регулярно осматриваться у окулиста и невролога. 